\section{Expand fundraising by Brazil's institutes}

It is time for Brazil's cash-strapped universities to embrace the fundraising campaigns that are common at prestigious institutions worldwide.

For instance, the money raised by Harvard University in Cambridge, Massachusetts, in its latest campaign (http:// campaign.harvard.edu) exceeds the individual annual budgets of two major Brazilian sciencefunding agencies. Furthermore, the $£ 1.2$ billion (US $\$ 2$ billion) raised by the University of Cambridge, UK, to mark its 800th anniversary in 2009 is comparable to the annual budget of the University of Sao Paulo.

Such initiatives are still unusual in Brazil, where government-funded universities are the main engine of higher education and science. The idea of private donations is widely regarded with suspicion, being perceived as a corrupt route for 'buying' illegal advantages or as potentially providing the state with an excuse to cut back investment.

A few of Brazil's leading academic institutions are starting to encourage private benefactors, so the challenge now is to increase that momentum and expand the fundraising enterprise.

Tiago Campos Pereira University of Sao Paulo, Brazil. tiagocampospereira@ffclrp.usp.br

\section{Stamina therapies: time to call a halt}

Mauro Ferrari, the nominated chair of a committee set up to evaluate the controversial stem-cell therapy used by Italy's Stamina Foundation, participated last month in a popular television programme, Le Iene (see Nature http://doi.org/rkj; 2014). Irrespective of the ambiguity of some of his comments, as explained in a Correction to your report, we believe that he should have declined the TV interview, given that Le Iene is widely seen as an advocate of Stamina.

Stamina's therapy has, incredibly, flouted all the laws and rules that are in place to protect patients. The health ministry's national institute (ISS) and the Italian Medicines Agency (AIFA) have already forbidden the clinical use of cells created by the Stamina procedure because of their failure to comply with safety standards.

We have written to the health ministry calling for an end to Stamina's stem-cell treatments. The ministry needs to explain to Parliament that a scientific committee is no longer necessary, in the face of evidence that 36 patients treated with the Stamina protocol whose clinical progress was followed by the Civil Hospital of Brescia - have shown no improvement.

Silvio Garattini Mario Negri Institute for Pharmacological Research, Milan, Italy. silvio.garattini@marionegri.it Giuseppe Remuzzi Mario Negri Institute, Bergamo, Italy. Gianluca Vago University of Milan, Italy. Alberto Zangrillo University Vita-Salute San Raffaele, Milan, Italy.

\section{Stamina therapies: let the record stand}

In our view, the Correction was not justified to your online News story reporting remarks made last month by Mauro Ferrari in a television interview about Italy's Stamina Foundation and its controversial stem-cell treatments (Nature http://doi. org/rkj; 2014). Ferrari is the proposed chair of the second scientific committee set to investigate the Stamina protocol.

First, we find it inappropriate that the Correction led to the removal of an ambiguous statement by Ferrari about the purported opportunities
Stamina's therapies might present for Italy.

Second, you corrected his alleged reference to Stamina as "the first important case for regenerative medicine [in Italy]", saying that he was in fact referring to the Stamina case as "the first important court case" in the country. However, there was no reference to a court case in Ferrari's statements in the TV interview as transmitted.

Ferrari also said in this interview that decisions following the committee's assessment would affect future generations of patients and "many other cases" to come. Regulation and approval of new therapies rests with the Italian Drug Agency operating within relevant laws, however, not with a scientific committee chair.

The Stamina case has made Italy a battlefield for local and international commercial interests and anti-regulatory lobbies. These misrepresent the regulation of new therapies as an obstacle to the rapid provision of cures to patients, rather than as a way of protecting people from abuse and fraud.

Last year, Italy came close to deregulating mesenchymal stemcell therapies (as supposedly used in Stamina's protocol) by reclassifying them as transplants, which would bypass the Italian Drug Agency and open the way to peddlers of unproven therapies. This was fortunately blocked by Italian scientists. The 2014 Public Service Award later granted to three of us (P.B., E.C. and M.D.L.) by the International Society for Stem Cell Research is a token of the global impact of the issues, as raised by many similar cases around the world.

Paolo Bianco Sapienza

University of Rome, Italy. paolo.bianco@uniroma1.it Elena Cattaneo University of Milan, Italy.

Michele De Luca University of Modena and Reggio Emilia, Modena, Italy.

Luca Pani Italian Medicines

Agency (AIFA), Rome, Italy.

Global fund needed for STEM education

To be competitive in today's global economy, developing countries need a workforce with a strong education in science, technology, engineering and mathematics (STEM). While the post-2015 United Nations development agenda is still under discussion, we propose that a global fund should be set up to back the most effective and innovative STEM programmes in the developing world and to improve the accessibility and quality of STEM education worldwide.

Existing STEM educational initiatives differ in their approach, scope, type, target populations and funding sources. A coordinated global STEM fund would bridge the gaps, provide more teachers, offer wider access to resources and programmes, stimulate innovation and recruit more women and students from minorities.

International organizations, such as the World Bank and the United Nations Educational, Scientific and Cultural Organization (UNESCO), could help to realize this STEM fund by providing crucial infrastructure, including access to the global educational network and to the management, financial and technical support it would need to begin operations.

Fanuel Muindi Massachusetts Institute of Technology, Cambridge, USA. fmuindi@mit.edu Moytrayee Guha Brigham and Women's Hospital, Harvard Medical School, Boston, USA.

CONTRIBUTIONS

Correspondence may be sent to correspondence@ nature.com after consulting the guidelines at go.nature.com/cmchno Alternatively, readers may comment online: www.nature.com/nature. 